\title{
Tourism flows and trade theory: a panel data analysis with the gravity model
}

\author{
Kiyong Keum
}

Received: 26 May 2008 / Accepted: 12 October 2008 / Published online: 7 November 2008

(C) Springer-Verlag 2008

\begin{abstract}
International trade represents the transnational flow of merchandise, while international tourism is the flow of humans from one country to another. This paper analyzes the trade and tourism flows to assess whether typical trade theories can be a theoretical basis in explaining tourism flow. Using a panel data analysis approach, this paper examines the gravity model and the Linder hypothesis regarding the two international flows in Korea. The empirical results provide evidence supporting the gravity model in terms of applicability and robustness to the flow of trade and tourism. The Linder hypothesis, however, fails to have the same result. Based on the gravity model, this paper elucidates a general explanation about the patterns of international tourism flows.
\end{abstract}

JEL Classification $\quad \mathrm{C} 21 \cdot \mathrm{C} 23 \cdot \mathrm{F} 11 \cdot \mathrm{F} 14 \cdot \mathrm{R} 12$

\section{Introduction}

Since the 1990s, the globalization and market liberalization trends have spurred international flows of goods and services more and more. The most conspicuous results were the emergence of two new kinds of entities in 1995 pertaining to international trade agreements: bilateral free trade agreements (BFTA) and the general agreement on trade in services (GATS). These international entities clearly demonstrate that the trend of trade liberalization in services as well as goods is vigorously underway in the global market, beyond regional economies or boundaries.

As a major part of international transactions in the service sector, the international tourism industry could not be indifferent to global trends. Terminologically, tourism

K. Keum (ه)

Seoul Development Institute, 391 Seocho-dong, Seocho-gu, Seoul, South Korea

e-mail: kykeum@sdi.re.kr 
can be differentiated from travel. However, the two terms are considered to be synonymous in the current paper under the tourist definition of the World Tourism Organization (WTO, 2006), in which travel purposes include leisure, visits, medical or health, study, religion, sport, business, and work assignments. According to WTO statistics, the magnitude of international tourist arrivals worldwide increased from 536 million in 1995 to 803 million in 2005, an increase of 50\%. Likewise, receipts from worldwide tourists in 2005 amounted to US \$676 billion, a 67\% increase since 1995. These statistics indicate that the contribution of international tourism to the global economy is remarkable.

However, there is a need to think about whether those figures truly demonstrate good meanings in the global economy. One issue raised here is the geographical imbalance in international tourism flows. In $2005,55 \%$ of total international tourist arrivals worldwide converged in the European region, while the portion of other travel to other regions remained relatively small: Asia and the Pacific region (19\%), Americas (17\%), Africa (4.7\%), and Middle East (4.8\%). Are there specific factors or forces driving this global travel pattern? The current paper examines whether a country has developed more active international tourism and trade transactions with geographically adjacent countries or with larger economies, and whether the tourism flows are more related to countries with similar income.

Another issue to consider is whether there is a theoretical model to generally explain international tourism flows, especially based on well-defined theory, as seen in the field of trade economics. So far, international trade theories seem to play a theoretical basis in explaining international tourism transactions (see Gray 1970; Socher 1986; Vellas and Becherel 1995). Gray (1970) argues that international transactions in travel services would conform to the mainstream theory of international trade flows, but adds that any orthodox international trade theory may give a partial explanation for international travel flows. If international travel flows conform to the theory of trade, an assumption that the mechanism of international merchandise flow is the same as that of international tourist flow is necessary. However, concrete evidence showing a theoretical and empirical coincidence between the two flows has not yet been presented.

In the context of international tourism research, most papers have focused on tourism demand modeling or choice modeling, dealing with typical influential factors of international tourism, such as exchange or interest rate, price, income, leisure time, and other psychological factors. However, since those models explain international tourism mostly with the demand factors or tourists' behavior in a certain time, geographical set, or specific case, a general explanation about the tourism flows could not be pulled out.

Accordingly, the current study explores the applicability of international trade theories to international tourism flows. In doing so, this study attempts to find a relevant theory which can elucidate a general explanation regarding global tourism flows. For the theoretical framework, this study examines two international trade theories: the gravity model, which is known as a spatial interaction model, and the Linder hypothesis, which is one of the alternative theories in international trade. As an empirical study, this paper employs the international tourism and trade flows in Korea. An econometric technique, i.e., the panel data analysis approach, is used to analyze cross-sectional and time series data at the same time. Actually, this paper is the first attempt to examine 
the validity of applying the theories regarding international merchandise flow to international tourist flow.

\section{Theoretical framework}

New theories prompt researchers to conduct intensive empirical investigations. When they meet difficulties in finding empirical validity for those theories, they divert their efforts to developing new theories. In the same way, the weakness in supporting the neoclassical trade theory, the so-called 'Heckscher-Ohlin (H-O) model', drove a number of economists to introduce new alternative theories, as they had done following the earlier Ricardian trade model. The alternative trade theories attempted to produce new theoretical explanations for shortcomings of the $\mathrm{H}-\mathrm{O}$ model with the problematic assumptions such as no trade barriers or transport costs, homogeneous production function, constant returns to scale, and perfect competition.

\subsection{Linder hypothesis}

In the early 1960s, Linder (1961) offered an alternative trade model, explaining international trade patterns as a demand-based theory, while the preceding classical Ricardian model and neoclassical H-O model mainly focused on the supply side. Linder's (1961) presupposition is that, as the similarity of per capita income between countries increases, their demand propensities become more similar. Therefore, according to Linder's hypothesis, the more similar the per capita income levels and demand patterns between countries, the greater the volume of trade between the two will be. This is the so-called "Linder hypothesis or theory" or "income similarity model".

Neoclassical trade theory (H-O model) maintains that comparative advantage for trading goods in international market is determined by the difference in factors' price caused by the difference in each country's relative capacity for production. Since, according to the $\mathrm{H}-\mathrm{O}$ model, such differences are generally larger between developed and developing countries than among developed or developing countries, a larger volume of trade is expected between developed and developing countries. Unlike the $\mathrm{H}-\mathrm{O}$ theory, however, the Linder hypothesis states that the volume of trade is expected to be larger among developed countries whose per capita incomes and tastes are similar than between developed and developing countries.

A number of researchers have attempted to test the Linder hypothesis, but the results were mixed until the 1980s. In earlier times, most studies provided little or no evidence for the hypothesis (e.g., Greytak and McHugh 1977; Kennedy 1980). One of the main arguments during the early period was that Linder and his supporters did not take the effect of distance (geographical effect) in trade into account. However, some empirical results have supported the Linder hypothesis, including the distance variable (e.g., Hirsch and Lev 1973; Hanink 1988; Bergstrand 1990).

Another controversial issue regarding the Linder hypothesis is that it can be applied only to developed countries where income is relatively high (Thursby and Thursby 1987; Linnemann and Van Beers 1988). However, some studies also provide evidence in favor of the hypothesis even in the case of developing countries (Aron and Weinblatt 
1998; Chow et al. 1999; McPherson et al. 2001). Generally, the Linder model received criticism from many studies until the 1980s, but, since the 1990s, many studies provide support for the Linder theory.

A possible reason for such mixed results comes from the different interpretations of the Linder model, in that he did not put forward his model with a formal specification. The results also vary according to empirical case groups, such as studies using data from the EU, ASEAN, NICs, or African countries. The Linder effect appears to be strong in regions with an economic union or integration, as most FTA blocs show. For this, some economists argue that globalization and economic integration trends seem to strengthen the Linder model (e.g., Choi 2002). Although Linder did not consider the distance factor between trading partners in his thesis, however, the distance variable is an important factor in limiting trade flows, and is a more powerful influence than income similarity (Fortune 1971). This implies that unbiased sampling for empirical cases is crucial for excluding the geographical noise of samples in terms of analytical validity, when models for testing the Linder effect considers the distance effect. Many studies have tested the Linder effect in international trade flows, and the work continues.

\subsection{The gravity model and international trade}

Most traditional international trade theories or new alternative theories are limited in providing a general and down-to-earth explanation for international trade flows. For example, the Ricardian model would be appropriate in explaining the trade pattern of goods from a primary industry for natural resources or a secondary industry for simple raw materials processing or assembling (Perdikis 1998). Similarly, the H-O model would be adept within an industry pertaining to the standardized manufacturing process for which the reduction of factor costs is a prime consideration. The Linder model is likely appropriate for explaining the trade patterns among developed countries in which capital availability is correlated with the level of income.

A common item among aforementioned trade theories is that they do not take an important trade factor into account: the distance effect. The initial attempt to apply a spatial interaction theory in physics, the so-called 'gravity model', to international trade studies in the economics field was done in a treatise on the location and trade theory by Isard (1954). Given the Isard's gravity concept in international economics, the general formula can be expressed as:

$$
F_{i j}=g \frac{m_{i} m_{j}}{d_{i j}^{2}}
$$

where $F_{i j}$ is the gravitational force (trade flow) between two objects (countries) $i$ and $j ; m_{i}$ and $m_{j}$ are respective mass (economic sizes) of the two countries; $d_{i j}$ is the distance as a resistance factor between the two; and gis the gravitational constant. The gravity theory for trade flows can be described in its simplest definition as follows: trade flows between two countries are proportional to the scale of their economies and inversely affected by the distance between the partners. Since spatial interaction 
means the gravitational force which is characterized by the masses of two points and their distance, the mass here can be expressed as opportunities, capacities, or attractions which cause the interactions. Thus, the term of mass can be replaced by many other forms of proxies that are dependent upon the characteristics of interactions, such as economy size, population, income level, purchasing power, and so on (Isard et al. 1998).

In many relevant literature streams, the most prevalent comment regarding the gravity model is that it is empirically the most successful trade model, although some papers have argued the model's drawbacks-i.e., lack of theoretical foundation or weak link between theory and empirical cases (see Deardoff 1984; Frankel et al. 1996; Polak 1996). Their arguments imply that the gravity model is empirically, but not theoretically, plausible. However, since Isard's initiative of gravity theory in international trade studies, a number of economists have contributed to the development of theoretical foundations for the gravity model. Specifically, Tinbergen (1962) introduced a logarithmic form of the model in an attempt to determine normal patterns of international trade. Showing how the gravity equation can be theoretically derived from a four-equation partial equilibrium model of exports (supply) and imports (demand). Leamer and Stern (1970) derived a gravity equation from a probabilistic model of trade. One of the most important theoretical perspectives is that the model can identify meaningful overall trends in complex spatial interactions. In the 1990s, Sen and Smith (1995) contributed to the establishment of a general theoretical foundation of the gravity model.

Frankel et al. (1996) has given three reasons for the success of the gravity model as follows: its empirical success in predicting bilateral trade flows; improved theoretical foundation arising from modern theories of trade; and a new interest among economists in the geography and trade fields in seeking to treat countries or regions as physically existing entities in a particular space. Likewise, Deardorff (1995) pointed out that "it is certainly no longer true that the gravity equation is without a theoretical basis." Actually, these are the economists who previously asserted the weak theoretical foundation of the gravity model.

With such theoretical and empirical support, the gravity model has been used for many research topics and purposes. An example of an empirical application of the gravity model includes the international immigration study of Karemera et al. (2000). The model has also been used to test or measure the effects of specific factors in international trade, such as technology, infrastructure, spatial factor, and so on (e.g., Eaton and Kortum 1997; Bougheas et al. 1999; Porojan 2001). Many attempts have been made to identify the impact of economic sanctions or discriminatory trade arrangements in international trade through the gravity model (e.g., Oguledo and MacPhee 1994; Wall 1999; Yang et al. 2004). In addition, a subject associated with economic or political union trends worldwide has also been a prevalent topic among international economists using the gravity model (e.g., Bikker 1992; Endoh 1999; Byers et al. 2000).

By now, there is no doubt that the gravity model is indispensable for analyzing the flows of spatial interactions. Although many people may believe that cutting-edge technologies have enabled international flows to move more frequently and quickly, the world is not getting dramatically smaller. This implies that the effect of distance in 
international trade flows would not be diminished overtime. The gravity equations tell us something important about what happens in international merchandise and human flows.

\section{Econometric framework}

This paper adopts the panel data regression approach for testing trade theories with respect to tourism flow through the gravity model. This pooled data analysis combining cross-sectional and time series data enables us to concurrently estimate differences across countries as well as over time. Typically, panel data regression has three kinds of models: pooled ordinary least square model (POLS), fixed-effects model (FEM), and random-effects model (REM). These are largely distinguished from the way of how the intercept term is treated, the term that represents the effects of variables excluded in the model. To use the panel analysis approach, it is necessary to decide what model is appropriate for the study and check prerequisites of the approach.

\subsection{Panel data regression models}

The POLS model is based on the assumption that both the intercept and coefficient for each individual are constant across cross-sectional individuals in the POLS equation. Instead of the homogeneous intercept in the POLS model, the fixed-effects model (FEM) allows for heterogeneous intercepts across cross-sectional individuals and/or over time using a differential intercept dummy. This means that each cross-sectional unit has its own individual specific parameter, or so-called individual fixed-effects, as follows:

$$
\begin{gathered}
\mathrm{Y}_{i t}=\alpha_{i t}+\beta \mathrm{X}_{i t}+\varepsilon_{i t}(i=1, \ldots, \mathrm{N} ; t=1, \ldots, \mathrm{T}) \\
\text { s.t. } \alpha_{i t}=\lambda_{0}+\sum_{i=1}^{\mathrm{N}-1} \lambda_{i} D M_{i}+\zeta_{0}+\sum_{t=1}^{\mathrm{T}-1} \zeta_{t} D M_{t}
\end{gathered}
$$

where $\alpha_{i t}$ is the fixed intercept term in which the intercept of the cross-sectional individual is heterogeneous over time (i.e., time variant); $\lambda_{0}$ and $\zeta_{0}$ in the sub-equation represent the base intercepts of individual $(i)$ unit and time $(t)$, respectively; $\lambda_{i}$ and $\zeta_{t}$ are the differential intercept coefficients which vary across cross-sectional individuals and over time, respectively; and $D M_{i}$ and $D M_{t}$ are the differential intercept dummies which indicate cross-sectional individual and time, respectively.

While FEM can estimate individual and/or time-specific effects from time- and individual-variant variables, however, it cannot detect the individual-specific effects regarding the individual-variant but time-invariant variables such as the distance variable between two trade partners in the gravity model. In addition, this model cannot capture time-specific effects for variables which are variant over time but invariant across individuals. Thus, respective time or individual specific effects for the invariant variables are subsumed under the intercept term. Another critical issue with this 
FEM is that it should produce several dummy variables, which would cause a degreesof-freedom problem, leading to an increase of the standard error in the regression equation.

An alternative FEM model expresses the specific effects for time- or individualinvariant variables as random variables (error terms) in the equation, instead of expressing the fixed intercept as the unobserved effects in FEM. This is the so-called random-effects model (REM) or error components model (ECM).

REM can estimate either individual- or time-specific effects of certain variables even though they are either individual-specific but time-invariant variables or timespecific but individual-invariant variables, any of which is impossible in FEM. In REM, such variables are treated as random variables with zero means and constant variance $\left(\sigma_{\lambda}^{2}, \sigma_{v}^{2}\right)$. Thus, as shown in Eq. (3), REM consists of a common intercept term $(\alpha)$, individual coefficients, and three random variables including an individual-specific error term $\left(\lambda_{i}\right)$, a time-specific error term $\left(v_{t}\right)$, and an error term which combines time and individual effects $\left(\varepsilon_{i t}\right)$. The basic formula of REM can be expressed as follows:

$$
\begin{aligned}
& \mathrm{Y}_{i t}=\alpha+\beta \mathrm{X}_{i t}+\omega_{i t}(i=1, \ldots, \mathrm{N} ; t=1, \ldots, \mathrm{T}) \\
& \text { s.t. } \omega_{i t}=\lambda_{i}+v_{t}+\varepsilon_{i t}
\end{aligned}
$$

where $\lambda_{i}$ is the unobserved individual-specific random effects, independently and identically distributed with zero mean with variance, $\sim \operatorname{IID}\left(0, \sigma \lambda^{2}\right) ; v_{t}$ represents the unobserved time-specific random effects, $\sim \operatorname{IID}\left(0, \sigma v^{2}\right)$; and $\varepsilon_{i t}$ is the remainder error term, $\sim \operatorname{IID}\left(0, \sigma \varepsilon^{2}\right)$. Equation (3) shows the two-way random effects model including both time- and individual-specific error term. In REM, individual- and time-specific effects indicate how much the respective effects deviates from the common intercept value. It is common for all coefficients in REM to be derived by the feasible generalized least squares (FGLS) method.

Actually, REM seems to be better for panel data analysis with the gravity model which includes both time- and individual-invariant variables. Furthermore, if a pooled model has random effects but ignores them, producing homogeneous parameters through simple POLS regression, huge bias results in the estimates (Moulton and Randolph 1989). Thus, when using the panel data model, a process is required to find out whether a pooled equation has random effects. The process includes the Hausman or Lagrange multiplier (LM) tests, which is part of the criteria for deciding whether to use FEM or REM.

\subsection{Lagrange multiplier test}

Although Mundlak (1978) argued that the individual-specific effects in the pooling model should always be treated as random effects, econometric techniques have been developed to single out a proper model out of the REM, FEM, or POLS models for panel data analysis. For example, Hausman (1978) devised a specification to test for orthogonality between the random effects by GLS and the fixed effects by OLS. The Hausman test needs the estimates from both fixed and random effects models. 
However, the fixed effects are not available from the gravity model. As another technique to detect the random effects in pooled models, Breusch and Pagan (1980) developed the Lagrange multiplier (LM) test, which is based on the combined time series $(t)$ and cross-sectional $(i)$ residuals $\left(\varepsilon_{i t}\right)$ from the pooled ordinary least square (OLS) regression. The null hypothesis and test statistic are as follows:

$$
\begin{aligned}
\mathrm{H}_{0}: \sigma_{\lambda}^{2}= & \sigma_{v}^{2}=0\left(\text { or } \operatorname{Corr}\left[w_{i t}, \mathrm{w}_{i s}\right]=0\right) \\
\mathrm{LM}= & \frac{\mathrm{NT}}{2}\left\{\frac{1}{\mathrm{~T}-1}\left[\frac{\sum_{i=1}^{\mathrm{N}}\left[\sum_{t=1}^{\mathrm{T}} \varepsilon_{i t}\right]^{2}}{\sum_{i=1}^{\mathrm{N}} \sum_{t=1}^{\mathrm{T}} \varepsilon_{i t}^{2}}-1\right]^{2}\right. \\
& +\frac{1}{\mathrm{~N}-1}\left[\frac{\sum_{t=1}^{\mathrm{T}}\left[\sum_{i=1}^{\mathrm{N}} \varepsilon_{i t}\right]^{2}}{\sum_{i=1}^{\mathrm{N}} \sum_{t=1}^{\mathrm{T}} \varepsilon_{i t}^{2}}-1\right]
\end{aligned}
$$

Under the null hypothesis, the LM statistic follows a chi-square distribution with two degrees of freedom, $\chi^{2}(2)$. If the null hypothesis cannot be rejected, i.e., $\sigma_{\lambda}^{2}=\sigma_{\nu}^{2}=0$, then the estimates of REM are not statistically different from those of the pooled OLS model. The variances, $\sigma_{\lambda}^{2}$ and $\sigma_{v}^{2}$, are of cross-section error and time-series error, respectively. Actually, the LM test is a necessary condition for the panel regression model.

\section{Model specification and data}

Based on the logarithmic form of the gravity model by Tinbergen (1962) and Linneman (1966) laid the foundation of theoretical justification for the model and introduced a gravity equation derived from a quasi-Walrasian general equilibrium model of export supply and import demand flows, which became a basic form of the gravity model in many studies thereafter. The following is the Linnenman's exponential regression form of the gravity model.

$$
X_{i j}=\delta_{0} Y_{i}^{\delta 1} N_{i}^{-\delta 2} Y_{j}^{\delta 3} N_{j}^{-\delta 4} D_{i j}^{-\delta 5} P_{i j}^{\delta 6}
$$

where $X_{i j}$ is the trade flow between country $i$ and $j ; \delta_{0}$ is a constant; $Y_{i}$ and $Y_{j}$ are gross national production in $i$ and $j$, respectively; $N_{i}$ and $N_{j}$ are population in $i$ and $j$; $D_{i j}$ is geographical distance between $i$ and $j ; \mathrm{P}_{i j}$ is preferential trade factor between $i$ and $j$; and $\delta_{1}, \delta_{2}, \delta_{3}, \delta_{4}, \delta_{5}, \delta_{6}$ are coefficients.

Since the Linneman's gravity equation, many studies for international interactions have used the gravity variables including a combination of variables representing economic mass: for instance, GDP and GDP per capita, or GDP and population. Although they have been widely used in trade studies, however, there is a possibility that the combination brings about a multicollinearity problem in a single regression equation. One thing to be noted here is that Linneman actually ignored the price effect in the gravity model because no country can have 'too low' or 'too high' price level 
in the long run in an open and competitive international market. This results from adaptation process through changes in the exchange rate.

This paper employs Linneman's gravity equation as a basic model but uses GDP variables without population variables in representing the economic size of each country. In addition, all gravity equations are estimated in the form of a log-linear equation, which can be converted from the exponential regression equations like the Linneman's equation. One of the attractive features in using the log-linear form is that it allows direct comparison with the parameter estimates among different models including the same variables, since the coefficients in such log-linear equations indicate the percentage change in dependent variable $(Y)$ for a given percentage of change in a explanatory variable $(X)$ or, in other words, the elasticity of $Y$ with respect to each $X$. Lastly, all gravity equations in this paper are analyzed through the two-way random effects (or error components) model, which addresses both cross-sectional and time effects.

\subsection{Model specification}

The gravity equations in this paper are modified by adding the Linder effect variable, i.e., income similarity effect, to the basic gravitational variables such as economic mass and distance in the standard gravity model. As mentioned, the modified gravity equations are used in an attempt to find out whether the Linder hypothesis for international goods flows can also be applied to explain international tourism flows. The Linder variable is quantified as the difference of real GDP per capita (GDPC) between two trading partners.

This study analyzes not only the aggregate tourism flow, but also its sub-flows specified by directions and purposes. In doing so, partial tourism flows as well as the whole tourism flow can be analyzed in order to identify the mechanism of overall tourism flows. Taking the log-linear form, the basic gravity equation for tourism flow can be expressed as follows:

$$
\begin{aligned}
\ln \left(\text { Tourism }_{k j t}\right)= & \beta_{0}+\beta_{1} \ln \left(\mathrm{GDP}_{k t}\right)+\beta_{2} \ln \left(\mathrm{GDP}_{j t}\right) \\
& +\beta_{3} \ln \left(\mathrm{DIS}_{k j}\right)+\beta_{4} \ln \left(\mathrm{LD}_{k j t}\right)+\psi_{k j t}
\end{aligned}
$$

where $\mathrm{GDP}_{k t}$ and $j t$ are the real gross domestic product of respective country $k$ and $j$ at time $t$; DIS $k j$ represents geographical distance between country $k$ and $j$ based on nautical miles between capital cities. One nautical mile is the angular distance of a minute of arc on the earth's surface; $\mathrm{LD}_{k j t}$ is the Linder variable, i.e., $\left(\mathrm{GDPC}_{k t}-\right.$ $\left.\mathrm{GDPC}_{j t}\right)^{2}$.

The basic Eq. (6) transforms to the aggregate tourism flow model ( $\left.\mathrm{AT}_{k j t}\right)$ and two sub-tourism flow models including outbound tourism flow $\left(\mathrm{OT}_{k j t}\right)$ from country $k$ and inbound tourism flow ( $\mathrm{IT}_{j k t}$ ) into country $k$, respectively. In addition, they are further divided into four sub-models by both travel purpose and direction, such as outbound leisure tourism flow $\left(\mathrm{OLT}_{k j t}\right)$, inbound leisure tourism flow (ILT $j k t$ ), outbound business tourism flow $\left(\mathrm{OBT}_{k j t}\right)$, and inbound business tourism flow $\left(\mathrm{IBT}_{j k t}\right)$, respectively. This is a multi-stage analysis to look into the mechanism of international tourist flows pertaining to gravity theory and Linder's hypothesis. The following 
illustrates the respective equations.

$$
\begin{aligned}
& \ln \left(\mathrm{LOT}_{k j t}\right), \ln \left(\mathrm{LIT}_{j k t}\right), \ln \left(\mathrm{BOT}_{k j t}\right), \text { and } \ln \left(\mathrm{BIT}_{j k t}\right) \\
& =\delta_{0}+\delta_{1} \ln \left(\mathrm{GDP}_{k t}\right)+\delta_{2} \ln \left(\mathrm{GDP}_{j t}\right)+\delta_{3} \ln \left(\mathrm{DIS}_{k j}\right)+\delta_{4} \ln \left(\mathrm{LD}_{k j t}\right)+\omega_{k j t}
\end{aligned}
$$

Since these equations are to be analyzed through the two-way random effects model of panel analysis approaches, the error terms, $\psi_{k j t}$ of Eq. (6) and $\omega_{k j t}$ of Eq. (7), consist of three components, as follows:

$$
\psi_{k j t}=\lambda_{1 k j}+v_{1 t}+\varepsilon_{1 k j t}, \omega_{k j t}=\lambda_{2 k j}+v_{2 t}+\varepsilon_{2 k j t}
$$

where $\lambda_{k j}$ is the unobserved cross-section (or country) specific error term; $v_{t}$ is the unobserved time-specific effects error term; and $\varepsilon_{k j t}$ represents the stochastic error term reflecting the effects of all remaining unobserved variables.

In an empirical study, one important process is anticipating the signs of parameter estimates in the equations. According to gravity theory in international economics, the volume of bilateral transactions in goods and services will be proportional to the economic size of trading partners, but inversely related to the geographical distance between the two. Accordingly, in the gravity equations for international tourism flows, the basic gravitational variables are expected to have a positive sign for the GDP variable and a negative sign for the distance variable. As for the Linder variable, its coefficient is expected to be negative, which implies that a smaller difference in real GDP per capita between the trading partners drives more tourism flows between the two. The empirical results will demonstrate which of the two international trade theories, gravity theory or Linder theory, is more applicable to international tourism flows.

\subsection{Data}

The empirical analysis is done for the case of bilateral tourism transactions between South Korea as a reference country and its 28 major trading partners worldwide. One country, Norway, was dropped in the four equations in Eq. (7) because the bilateral tourism flow data by travel purposes for the country was partly unavailable. In addition, some countries were initially excluded from this analysis. These are former or current socialist/communist countries, including China, Vietnam, Russia, and Eastern European countries, and the African countries where transactions with them are relatively very scarce. Since market distortion occurs in such centrally controlled regimes, most economic theories for free market systems are inapplicable.

This study sets the time period from 1990 to 2002 for trade and tourism data. There are two reasons for this period. First is that Korean outbound leisure tourism flow was not fully liberalized until the government eliminated partial restrictions on outbound travel in 1989. The other reason is that, in 2003, the so-called severe acute respiratory syndrome (SARS) disaster seriously struck the tourism market worldwide, especially in the East and Southeast Asian and North American regions. The SARS impact on the international tourism market at that time was so serious that the leisure tourism market worldwide was nearly frozen in the summer of 2003. 
Table 1 The LM test results

\begin{tabular}{|c|c|c|c|c|c|}
\hline \multicolumn{4}{|l|}{ Models } & \multirow{2}{*}{$\frac{\mathrm{LM}}{1771.76}$} & \multirow{2}{*}{$\frac{N \backslash T}{28 \backslash 13}$} \\
\hline $\ln \mathrm{AT}$ & 3926.47 & 109.57 & 332.78 & & \\
\hline $\ln \mathrm{OT}$ & 8828.08 & 449.86 & 754.80 & 1736.23 & \\
\hline $\ln \mathrm{IT}$ & 2380.76 & 6.58 & 198.72 & 1834.91 & \\
\hline $\ln \mathrm{OLT}$ & 882.99 & 544.40 & 477.69 & 8.89 & $27 \backslash 7$ \\
\hline $\ln \mathrm{ILT}$ & 192.03 & 5.89 & 100.58 & 13.39 & \\
\hline $\ln \mathrm{OBT}$ & 317.64 & 25.54 & 165.54 & 12.97 & \\
\hline $\ln \mathrm{IBT}$ & 351.77 & 16.84 & 189.81 & 11.97 & \\
\hline
\end{tabular}

$\varepsilon_{i t}$ is the OLS residuals

The $95 \%$ critical value for $\chi^{2}(2)$ is 5.99

\section{Empirical results}

This section provides the empirical results from testing the two international trade theories, gravity model and the Linder hypothesis, with relevant econometric models for the international tourism flows in Korea. Before the main analysis, this paper carried out two preliminary tests. The first is a LM test with pooled regression estimates regarding bilateral tourism and trade flows. Second is a test to identify the compatibility between the two trade theories and the trade flows to and from Korea.

\subsection{Preliminary tests}

The LM test for all panel regression models was utilized. Based on the sum of squared residuals (RSS) from the POLS regressions, the LM statistics can detect the existence of individual- and time-specific random effects in the panel data. Following Table 1 reports the LM test results of the aggregate travel flow model (AT), outbound travel flow model (OT), inbound travel flow model (IT), and four sub-travel models by travel direction and purpose, including outbound leisure travel flow (OLT), inbound leisure travel flow (ILT), outbound business travel flow (OBT), and inbound business travel flow (IBTU), respectively.

As stated, the first three models (AT, OT, and IT) used a dataset pooling 28 crosssections and 13 time series from 1990 to 2002, while the remaining four models analyze pooled data including 27 cross-sections and 7 time series from 1996 to 2002 as a result of data availability and continuity. All of the models commonly take a modified gravity model including the Linder variable.

Table 1 shows that all LM statistics across models are greater than the critical value, 5.99 , at the $95 \%$ significance level for $\chi^{2}$ (2) under the null hypothesis. This leads to the rejection of the null hypothesis of "no random effects" in favor of the random effects model (REM). That means that the OLS regression approach with a single common intercept is inappropriate for the gravity equations in this paper.

Before going over the international tourism flows of Korea, another preliminary analysis was carried out for the international trade flows in Korea with the REM. This is an attempt to empirically examine how the gravity model and Linder hypothesis 
Table 2 Gravity and Linder effects in trade flows

\begin{tabular}{|c|c|c|c|c|c|c|}
\hline \multirow[t]{3}{*}{ Independent } & \multicolumn{6}{|c|}{ Dependents } \\
\hline & \multicolumn{2}{|l|}{$\ln$ Trade } & \multicolumn{2}{|c|}{$\ln$ Export } & \multicolumn{2}{|l|}{ lnImport } \\
\hline & Coeff. & $t$ & Coeff. & $\mathrm{T}$ & Coeff. & $\mathrm{T}$ \\
\hline $\ln G D P_{j}$ & $0.78^{*}$ & 7.39 & $0.80^{*}$ & 6.66 & $0.60^{*}$ & 4.79 \\
\hline $\ln G D P_{k}$ & $0.58^{*}$ & 2.89 & $0.44^{* *}$ & 1.82 & $0.77^{*}$ & 4.03 \\
\hline $\ln \mathrm{DIS}$ & $-1.05^{*}$ & -4.60 & $-1.14^{*}$ & -4.71 & $-0.90^{*}$ & -3.20 \\
\hline $\ln$ LINDER & $-0.06^{*}$ & -3.91 & $-0.09^{*}$ & -3.75 & $0.06^{*}$ & 2.70 \\
\hline Constant & $-11.87^{* *}$ & -2.11 & -8.15 & -1.21 & $-16.43^{*}$ & -3.01 \\
\hline Obs. $(n)$ & \multicolumn{2}{|c|}{364} & \multicolumn{2}{|c|}{364} & \multicolumn{2}{|c|}{364} \\
\hline$R^{2}$ weighted & \multicolumn{2}{|c|}{0.23} & \multicolumn{2}{|c|}{0.19} & \multicolumn{2}{|c|}{0.18} \\
\hline$R^{2}$ unweighted & \multicolumn{2}{|c|}{0.59} & \multicolumn{2}{|c|}{0.54} & \multicolumn{2}{|c|}{0.56} \\
\hline \multicolumn{7}{|l|}{ Effects Specification } \\
\hline Cross-section random $\mathrm{SD} \backslash$ Rho & \multicolumn{2}{|l|}{$0.76 \backslash 0.89$} & \multicolumn{2}{|c|}{$0.79 \backslash 0.81$} & \multicolumn{2}{|c|}{$0.93 \backslash 0.91$} \\
\hline Period random $\mathrm{SD} \backslash$ Rho & \multicolumn{2}{|l|}{$0.14 \backslash 0.03$} & \multicolumn{2}{|c|}{$0.16 \backslash 0.03$} & \multicolumn{2}{|c|}{$0.12 \backslash 0.02$} \\
\hline Idiosyncratic random $\mathrm{SD} \backslash$ Rho & \multicolumn{2}{|l|}{$0.23 \backslash 0.08$} & \multicolumn{2}{|c|}{$0.35 \backslash 0.16$} & \multicolumn{2}{|l|}{$0.25 \backslash 0.07$} \\
\hline
\end{tabular}

Method: Pooled EGLS (Two-way random effects)

Rho indicates respective portion of the sum of standard deviations squared

$*$ and $* *$ Significance at the 1 and $5 \%$ levels, respectively

work in the cases of Korean bilateral trade flows. In Table 2, all parameter coefficients are statistically significant. The results demonstrate the empirical evidence supporting the trade theories. The gravity variables over the three trade models for aggregate trade, exports, and imports, respectively, show the signs expected by Isard (1954), which means that gravity theory fits the data on overall Korean trade flows.

As for the Linder effect in Korean trade flows, however, there is an exception for the import flow. The coefficient of the Linder variable in the import equation has a positive sign, which is contrary to the Linder theory, while the same coefficients in other equations have negative signs. This means that the Korean import flow provides evidence against Linder's hypothesis. One possible explanation for the result against the Linder hypothesis in the Korean import flow can be found in Korea's major import countries and volumes. Among top 5 importing partners of Korea including Japan, USA, Germany, Australia, and Indonesia, the per capita incomes of the first four countries are much higher than that of Korea, while Indonesian per capita income is much lower than Korean income.

This means that Korea imports goods and services mostly from countries with a higher or lower per capita income than Korea, rather than from countries with a income level similar to Korea. Although the results are mixed in the two disintegrated trade models, the aggregate trade model provides empirical evidence supporting the Linder hypothesis. Accordingly, in terms of aggregate trade volume, it can be said that the international trade flows in Korea increase when the trade partners have per capita income which is similar to Korea, as argued by Linder. 
Table 3 Gravity and Linder effects in international tourism flows

\begin{tabular}{|c|c|c|c|c|c|c|}
\hline \multirow[t]{3}{*}{ Independent } & \multicolumn{6}{|c|}{ Dependent } \\
\hline & \multicolumn{2}{|l|}{$\ln \mathrm{AT}$} & \multicolumn{2}{|l|}{$\ln \mathrm{OT}$} & \multicolumn{2}{|l|}{$\ln \mathrm{IT}$} \\
\hline & Coeff. & $t$ & Coeff. & $\mathrm{T}$ & Coeff. & $\mathrm{T}$ \\
\hline $\ln \mathrm{GDP}_{j}$ & $0.62^{*}$ & 4.63 & $0.77^{*}$ & 3.84 & $0.69^{*}$ & 6.86 \\
\hline $\ln \mathrm{GDP}_{k}$ & $1.20^{*}$ & 9.15 & $2.26^{*}$ & 8.25 & $0.47^{*}$ & 6.14 \\
\hline $\ln \mathrm{DIS}$ & $-1.97^{*}$ & -6.65 & $-2.07^{*}$ & -4.72 & $-1.99^{*}$ & -8.82 \\
\hline $\ln \mathrm{LINDER}$ & $0.04^{*}$ & 2.09 & $0.06^{* *}$ & 2.14 & 0.02 & 1.21 \\
\hline Constant & $-22.69^{*}$ & -5.64 & $-55.76^{*}$ & -7.04 & $-5.11^{* *}$ & -1.89 \\
\hline Obs. $(n)$ & \multicolumn{2}{|c|}{364} & \multicolumn{2}{|c|}{364} & \multicolumn{2}{|c|}{364} \\
\hline$R^{2}$ weighted & \multicolumn{2}{|c|}{0.43} & \multicolumn{2}{|c|}{0.30} & \multicolumn{2}{|c|}{0.51} \\
\hline$R^{2}$ unweighted & \multicolumn{2}{|c|}{0.69} & \multicolumn{2}{|c|}{0.56} & \multicolumn{2}{|c|}{0.77} \\
\hline \multicolumn{7}{|l|}{ Effects Specification } \\
\hline Cross-section random $\mathrm{SD} \backslash$ Rho & \multicolumn{2}{|l|}{$0.98 \backslash 0.92$} & \multicolumn{2}{|c|}{$1.47 \backslash 0.91$} & \multicolumn{2}{|c|}{$0.76 \backslash 0.93$} \\
\hline Period random $\mathrm{SD} \backslash$ Rho & \multicolumn{2}{|l|}{$0.06 \backslash 0.00$} & \multicolumn{2}{|l|}{$0.17 \backslash 0.01$} & \multicolumn{2}{|c|}{$0.00 \backslash 0.00$} \\
\hline Idiosyncratic random SD $\backslash$ Rho & \multicolumn{2}{|l|}{$0.28 \backslash 0.08$} & \multicolumn{2}{|l|}{$0.43 \backslash 0.08$} & \multicolumn{2}{|c|}{$0.21 \backslash 0.07$} \\
\hline
\end{tabular}

Sample: Time series 13 (1990-2002); Cross-section 28

Method: Pooled EGLS (Two-way random effects)

Rho indicates respective portion of the sum of standard deviations squared

$*$ and ** Significant at the 1 and $5 \%$ levels, respectively

The statistics for the total of 41 individual- and time-specific random effects are omitted here due to limited space. They can be provided on individual request. At the bottom portion in the table, the estimates of the error component variances are reported. These are the standard deviations (SD) of the three error components. The SD values are based on logarithms in this study since the models are log-linear equations. The values of Rho $(\rho)$ comprise the ratio of each error component from the sum of all standard deviations squared.

Repeatedly, the parameter coefficients in the log-linear models represent the elasticity of each trade flow with respect to each independent variable.

\subsection{Gravitational and Linder effects in international tourism flows}

In this section, the gravity equations including the Linder variable are used to estimate the effects of both the gravity variables and the Linder variable at the same time. In Table 3 above, the coefficients of the gravity variables in all equations have the expected signs and all are strongly significant at the one percent level, all of which are similar to those in the trade equations. In the models for aggregate travel flow (AT) and inbound travel flow (IT), the distance elasticity is the largest, as was in all preceding trade flows. However, the outbound travel flow (OT) is more elastic to the Korean GDP variable than any other variable, unlike Korean goods import flow.

To put it another way, OT is influenced by the country's income level a little more than other variables, including geographical distance, while AT and IT are more affec- 
Table 4 Gravity and Linder effects in Korean sub-tourism flows

\begin{tabular}{|c|c|c|c|c|c|c|c|c|}
\hline \multirow[t]{3}{*}{ Independent } & \multicolumn{8}{|c|}{ Dependent } \\
\hline & \multicolumn{2}{|l|}{$\ln \mathrm{OLT}$} & \multicolumn{2}{|l|}{$\operatorname{lnILT}$} & \multicolumn{2}{|l|}{$\ln \mathrm{OBT}$} & \multicolumn{2}{|l|}{$\ln \mathrm{IBT}$} \\
\hline & Coeff. & $t$ & Coeff. & $t$ & Coeff. & $t$ & Coeff. & $t$ \\
\hline $\ln \mathrm{GDP}_{j}$ & $0.92^{*}$ & 3.08 & $0.80^{*}$ & 6.85 & $0.92 *$ & 5.98 & $1.04^{*}$ & 6.41 \\
\hline $\ln \mathrm{GDP}_{k}$ & $1.81^{*}$ & 4.17 & $0.90^{*}$ & 6.21 & $0.73^{*}$ & 4.43 & $0.32^{* *}$ & 1.35 \\
\hline $\ln \mathrm{DIS}$ & $-2.01^{*}$ & -3.45 & $-1.92^{*}$ & -8.70 & $-1.92^{*}$ & -6.43 & $-1.38^{*}$ & -4.67 \\
\hline $\ln$ LINDER & -0.08 & -1.95 & -0.01 & -0.46 & -0.01 & -0.56 & 0.04 & 1.35 \\
\hline Constant & $-46.30^{*}$ & -3.62 & $-20.21^{*}$ & -4.62 & $-19.47^{*}$ & -3.74 & -19.55 & -2.77 \\
\hline Obs. $(n)$ & \multicolumn{2}{|c|}{189} & \multicolumn{2}{|c|}{189} & \multicolumn{2}{|c|}{189} & \multicolumn{2}{|c|}{189} \\
\hline$R^{2}$ weighted & \multicolumn{2}{|c|}{0.22} & \multicolumn{2}{|c|}{0.52} & \multicolumn{2}{|c|}{0.41} & \multicolumn{2}{|c|}{0.29} \\
\hline$R^{2}$ unweighted & \multicolumn{2}{|c|}{0.38} & \multicolumn{2}{|c|}{0.79} & \multicolumn{2}{|c|}{0.66} & \multicolumn{2}{|c|}{0.68} \\
\hline \multicolumn{9}{|l|}{ Effects Specification } \\
\hline Cross-section random $\mathrm{SD} \backslash$ Rho & \multicolumn{2}{|l|}{$1.64 \backslash 0.96$} & \multicolumn{2}{|l|}{$0.76 \backslash 0.95$} & \multicolumn{2}{|c|}{$0.98 \backslash 0.96$} & \multicolumn{2}{|c|}{$1.03 \backslash 0.91$} \\
\hline Period random $\mathrm{SD} \backslash$ Rho & \multicolumn{2}{|l|}{$0.06 \backslash 0.00$} & \multicolumn{2}{|l|}{$0.00 \backslash 0.00$} & \multicolumn{2}{|l|}{$0.01 \backslash 0.00$} & \multicolumn{2}{|c|}{$0.00 \backslash 0.00$} \\
\hline Idiosyncratic random $\mathrm{SD} \backslash$ Rho & \multicolumn{2}{|l|}{$0.32 \backslash 0.04$} & \multicolumn{2}{|l|}{$0.18 \backslash 0.05$} & \multicolumn{2}{|l|}{$0.19 \backslash 0.04$} & \multicolumn{2}{|c|}{$0.31 \backslash 0.08$} \\
\hline
\end{tabular}

Sample: Time series 7 (1996-2002); Cross-section 27

Method: Pooled EGLS (Two-way random effects)

Rho indicates respective portion of the sum of standard deviations squared

* and ** Significant at the 1 and $5 \%$ levels, respectively

ted by the distance variable than others. These arguments are resulted from intra-model comparisons regarding explanatory variables' influence in terms of the respective elasticity of each tourism flow.

When it comes to inter-model comparisons between OT and IT, the elasticities of OT with respect to $\mathrm{GDP}_{j}, \mathrm{GDP}_{k}$, and distance, respectively, are all larger than those of IT, respectively. This implies that Korean outbound travelers are more responsive to percent changes in those variables than foreign travelers into Korea.

As for the Linder hypothesis, however, the results demonstrate explicit evidence which does not support the Linder hypothesis in the international tourism flows of Korea. Specifically, the AT and OT models give statistically significant estimates for the Linder effect, but the effect is positive, which contradicts Linder's hypothesis. The results imply that, unlike the international merchandise trading patterns in Korea, Korean outbound tourists likely travel more to the countries with which the difference of per capita income is larger. However, inbound tourism flow was indifferent to the per capita income similarity between Korea and the origin countries, while it is significantly affected by the gravitational variables.

Last, as shown in Table 4, the directional outbound and inbound tourism flows are further divided by travel purposes, i.e., leisure and business purposes, and became four basic units of tourism flows, such as outbound leisure tourism flow (OLT), inbound leisure tourism flow (ILT), outbound business tourism flow (OBT), and inbound business tourism flow (IBT). This multi-stage analysis enables us to look into the mechanism of tourism flow patterns. The results in Table 4 show that all explanatory variables produce statistically significant coefficients and have the expected signs across all 
models. This means that the gravity model is robust even in international tourism flow models.

As for the relationship between international tourism flows and Linder's theory, the Linder variable is still a problem even in the sub-flow models. The coefficients of the Linder variable in most flows have negative signs, with the exception of IBT, which is theoretically expected for the theory's validity, but no coefficient is statistically significant. This is somewhat different from the preceding results. The results indicate that the Linder theory is inconsistent across stages over the tourism flows, and, even in the subdivided flows, no tourism flow supports the Linder hypothesis.

When going over each variable's impact in each sub-flow, the percentage change of GDP $j$ influences IBT more than other flows, while $\mathrm{GDP}_{k}$ affects OLT more. This means that, when other countries' income grows, the foreign inbound tourism flow into Korea responded to the change more than any other flow. Likewise, as the income in Korea increases, the proportionate change occurs in the overseas leisure tourism flow of Korea. In addition, the outbound leisure flow shows the most sensitive response to the percentage change in distance in comparison to other flows. This implies that Korean leisure tourists give more preference to closer travel destinations than other types of tourists, and the distance variable is the most important factor over all subflows.

\section{Discussion and conclusions}

Before GATS, the term "international trade" usually designated transactions related to merchandise. However, as GATS implies, international service transactions are also important in international trade flows. One of the major flows in the service sector is international tourism including both business and leisure travel.

Tourism flow is a transnational movement of humans, while trade involves the flow of merchandise. Thus, the mechanism and pattern of international flows between tourism and trade would be different. Based on this presupposition, the current paper empirically examined international tourism flow, applying it to two international trade theories pertaining to the flow of goods. The main purpose is to assess the applicability of trade theories to tourism flows, or in other words, whether trade theory for the flow of goods can be a theoretical basis in explaining tourism flows as well. For this, the tourism flows to and from Korea were analyzed with respect to the gravity model and Linder model.

The results of the preliminary test for trade flows show that gravity theory proves to be suitable for overall trade flows including exports and imports in Korea. However, the Linder theory could not be supported because of the case of Korean import flow.

When it comes to the international tourism flows of Korea, however, the results are mixed. The international travel flows, including respective aggregate, outbound, and inbound travel flows, provide perfect evidence for gravity theory's validity and applicability to travel flows as well as to trade flows. Specifically, out of the three gravity variables in this study, the distance elasticity of all travel flows is larger than any other variable elasticity. This result shows the importance of the distance variable in international transactions, regardless of tourism or commodity flows, as Isard argued 
half a century ago. Unlike gravity theory, however, Linder theory failed to get evidence supporting it in the analysis of international travel flows in Korea.

This paper concludes that, based on the gravity model, the maldistributed pattern of global travel flows can be generally explained by economic size and distance between origin and destination. In other words, bilateral international tourism flows would take place more where the income or economic size of the origin and destination countries is larger and the distance between the two partners is closer. In addition, this paper found that the pattern of individual outbound or inbound flows can be different from that of the whole flow of aggregated individual flows. Accordingly, in bilateral or multilateral transaction studies, respective in- and out-bound flows and their aggregate flows should be considered separately.

Consequently, the implication of this study is twofold. In an academic aspect, this paper confirms the empirical robustness of the gravity model in international flows including goods and tourism, but does not provide support for the Linder theory in the same flows. More importantly, this study suggests a strong possibility that the gravity model can be a general international trade theory, although most other previous international trade theories have failed to provide a general and robust explanation for the patterns of international interactions as discussed in Sect. 2. As for the practical aspect, this study provides validity in using the gravity model for various international tourism studies, especially in the fields of international tourism economics and marketing pertaining to patterns of tourism flow, forecasting, relationships with other spatial interactions, comparative analysis, effects analysis, and so on, most of which have been done with the gravity model in the field of international economics.

Acknowledgments The author is specially grateful to his doctorate supervisor, Walter Isard, at Cornell University, who gave the author valuable comments and suggestions on an earlier draft of this paper. Acknowledgements are also due to Professor Isard for his devotion to the field of Regional Science and the two reviewers. The author dedicates this paper to Professor Isard.

\section{References}

Aron A, Weinblatt J (1998) Linder's hypothesis revisited: income similarity effects for low income countries. Appl Econ Lett 5:607-611. doi:10.1080/135048598354267

Bergstrand J (1990) The Heckscher-Ohlin-Samuelson model, the Linder hypothesis and the determinants of bilateral intra-industry trade. Econ J 100(403):1216-1229. doi:10.2307/2233969

Bikker J (1992) International and external trade liberalization in the EEC: an econometric analysis of international trade flows. Econ Appl 45:91-119

Bougheas S, Demetriades P, Morgenroth L (1999) Infrastructure, transport costs and trade. J Int Econ 47:169-189. doi:10.1016/S0022-1996(98)00008-7

Breusch T, Pagan A (1980) The Lagrange multiplier test and its applications to model specification in econometrics. Rev Econ Stud 47:239-253. doi:10.2307/2297111

Byers D, Íşcan T, Lesser B (2000) New borders and trade flows: a gravity model analysis of the baltic states. Open Econ Rev 11:73-91. doi:10.1023/A:1008305213791

Choi C (2002) Linder hypothesis revisited. Appl Econ Lett 9(9):601-605. doi:10.1080/13504850110111234

Chow P, Kellman M, Shachmurove Y (1999) A test of the Linder hypothesis in Pacific NICs trade 19651990. Appl Econ 31(2):175-182. doi:10.1080/000368499324408

Deardoff A (1984) Testing trade theories and predicting trade flows. In: Jones R, Kenen P (eds) Handbook of international economics, vol I, Chap. 10. North-Holland, Amsterdam, pp 467-513

Eaton J, Kortum S (1997) Technology and bilateral trade. NBER working paper series, No. 6253 
Endoh M (1999) Trade creation and trade diversion in the EEC, the LAFTA and the CMEA: 1960-1994. Appl Econ 31:207-216. doi:10.1080/000368499324435

Fortune J (1971) Some determinants of trade in finished manufactures. Swed J Econ 73:311-317. doi:10. $2307 / 3439168$

Frankel J, Romer D, Cyrus T (1996) Trade and growth in East Asian Countries: cause and effect? NBER working paper series, No. 5732

Gray H (1970) International travel-international trade. Heath Lexington Books, Lexington

Greytak D, McHugh R (1977) Linder's trade thesis: an empirical examination. Southern Econ J 43(3):138689

Hanink D (1988) An extended Linder model of international trade. Econ Geogr 64(4):322-334. doi:10. $2307 / 144231$

Hausman J (1978) Specification tests in econometrics. Econometrica 46:1251-1271. doi:10.2307/1913827

Hirsch S, Lev B (1973) Trade and per capita income differentials: a test of the Burenstam-Linder hypothesis. World Dev 1(9):11-17. doi:10.1016/0305-750X(73)90154-X

Isard W (1954) Location theory and trade theory: short-run analysis. Q J Econ 68:305-322. doi:10.2307/ 1884452

Isard W, Azis I, Drennan M, Miller R, Saltzman S, Thorbecke E (1998) Methods of interregional and regional analysis. Ashgate Publishing Co., Aldershot

Karemera D, Oguledo V, Davis B (2000) A gravity model analysis of international migration to North America. Appl Econ 32:1745-1755. doi:10.1080/000368400421093

Kennedy T (1980) An intertemporal test and rejection of the Linder hypothesis. South Econ J 46(3):898-903. doi: $10.2307 / 1057159$

Leamer E, Stern R (1970) Quantitative international economics. Allyn and Bacon, Boston

Linder S (1961) An eassy on trade and transformation. Almqvist \& Wiksells, Stockholm

Linnemann H (1966) An econometric study of international trade flows. North-Holland Publishing Co., Amsterdam

Linnemann M, Van Beers C (1988) Measures of export-import similarity and the Linder Hypothesis once again. Weltwirtsch Arch 124:443-457. doi:10.1007/BF02708659

McPherson M, Redfearn M, Tieslau M (2001) International trade and developing countries: an empirical investigation of the Linder hypothesis. Appl Econ 33:649-657. doi:10.1080/000368401750106243

Moulton B, Randolph W (1989) Alternative tests of the error components model. Econometrica 57:685-667. doi: $10.2307 / 1911059$

Mundlak Y (1978) On the pooling of time series and cross section data. Econometrica 46:69-85. doi:10. $2307 / 1913646$

Oguledo V, MacPhee C (1994) Gravity models: a reformulation and an application to discriminatory trade arrangements. Appl Econ 26(2):107-120. doi:10.1080/00036849400000066

Perdikis KW (1998) Trade theories and empirical evidence. Manchestar University Press, Manchestar

Polak J (1996) Is APEC a National Regional trade bloc?: a critique of the 'Gravity Model' of international trade. World Econ 19(5):533-543. doi:10.1111/j.1467-9701.1996.tb00695.x

Porojan A (2001) Trade flows and spatial effects: the gravity model revisited. Open Econ Rev 12:265-280. doi:10.1023/A:1011129422190

Sen A, Smith T (1995) Gravity models of spatial interaction behavior. Springer, Heidelberg

Socher K (1986) Tourism in the theory of international trade and payments. Tourist Rev 3:24-26. doi:10. $1108 / \mathrm{eb} 057953$

Thursby J, Thursby M (1987) Bilateral trade flows: the Linder hypothesis and exchange risk. Rev Econ Stat 69(3):488-495. doi:10.2307/1925537

Tinbergen J (1962) Shaping the world economy: suggestions for an international economic policy. The Twentieth Century Fund, New York

Vellas F, Becherel L (1995) International tourism: an economic perspective. St. Martin's Press, New York

Wall H (1999) Using the gravity model to estimate the costs of protection. Rev Fed Reserve Bank St. Louis 81(1):33-40

UNWTO (2006) UNWTO world tourism barometer, Vol 4(2). The World Tourism Organization

Yang J, Askari H, Forrer J, Teegen H (2004) U.S. Economic Sanctions: an empirical study. Int Trade J 18(1):23-62 doi:10.1080/08853900490277341 